\title{
DEVELOPING DESIGN GUIDELINES FOR COMMERCIAL VEHICLE ENVELOPES ON URBAN STREETS
}

\author{
EDWARD MCCORMACK, ANNE GOODCHILD, MANALI SHETH \& DAVID HURWITZ \\ University of Washington, Oregon State University, Oregon
}

\begin{abstract}
Commercial heavy vehicles using urban curbside loading zones are not typically provided with an envelope, or space adjacent to the vehicle, allocated for loading and unloading activities. While completing loading and unloading activities, couriers are required to walk around the vehicle, extend ramps and handling equipment and manoeuvre goods; these activities require space around the vehicle. But the unique space needs of delivery trucks are not commonly acknowledged by or incorporated into current urban design practices in either North America or Europe. Because of this lack of a truck envelope, couriers of commercial vehicles are observed using pedestrian pathways and bicycling infrastructure for unloading activities, as well as walking in traffic lanes. These actions put them and other road users in direct conflict and potentially in harm's way.

This article presents our research to improve our understanding of curb space and delivery needs in urban areas. The research approach involved the observation of delivery operations to determine vehicle type, loading actions, door locations and accessories used. Once common practices had been identified by observing 25 deliveries, simulated loading activities were measured to quantify different types of loading space requirements around commercial vehicles. This resulted in a robust measurement of the operating envelope required to reduce conflicts between truck loading and unloading activities with adjacent pedestrian, bicycle, and motor vehicle activities. From these results, commercial loading zone design recommendations can be developed that will allow our urban street system to operate more efficiently, safely and reliably for all users.

Keywords: freight, commercial vehicle load zones.
\end{abstract}

\section{INTRODUCTION}

There is continued pressure for multiple modes to share urban streets and compete for curb space as urban populations and freight activities grow. Cities are recognizing curb space as valuable public real estate that must be better understood, managed and designed in order to improve the quality of life for residents and the transportation systems of cities.

Cities are responsible for strategizing how best to manage, regulate and design curb space for different transportation modes and activities, including commercial vehicle parking and urban deliveries. These strategies are complex because they include a wide range of stakeholders and are further compounded by well-accepted urban planning policies (such as Smart Growth and Complete Streets) that support compact development, a mixture of land uses and a range of feasible transportation options that promote and facilitate modes of travel other than the automobile - e.g. transit, bicycles and walking [1,2]. Although these policies are well-intended, current application standards have significant gaps that do not fully support the unique infrastructure and design needs of freight activity and urban goods deliveries.

Previous studies and observations by the research team found that curb use by commercial vehicles is not aligned with designated curb allocation, and current allocation is not spatially allocated according to demand [3-5]. Common actions that reflect the limitations of curb space design for deliveries include commercial vehicle parking on sidewalks and in bike lanes and turn lanes, loading ramps and lift gates blocking crosswalks and sidewalks and the staging of freight in locations that impede bike and pedestrian movements. These 
problems occur because commercial vehicles using designated loading zones are not allocated an envelope, or space adjacent to the vehicle, to accommodate loading and unloading activities.

When performing delivery activities, couriers (i.e. delivery vehicle drivers and helpers) are required to walk around the vehicle, extend ramps and handling equipment and manoeuvre goods; all these activities require space around the vehicle beyond the dimensions of the vehicle itself. A parallel can be drawn with parking for disabled drivers, which allocates an extra buffer next to a disabled parking space allowing a wheelchair to exit/ enter the vehicle. However, unlike disabled parking, trucks are typically not allocated this buffer space, and as a result of these infrastructure insufficiencies, couriers undertake highrisk behaviours.

In obstructing pedestrian pathways and bicycle infrastructure to complete deliveries, couriers' actions create uncertainty, disrupt the predictable flow of traffic and put the driver and other road users in direct conflict and, ultimately, in harm's way. While North American data are unavailable, studies in the United Kingdom found that "every year, about 70 people are killed and 2000 seriously injured in accidents involving vehicles in and around workplaces. A significant number of these occur during deliveries and collections" [6].

There are no commercial vehicle load zone (CVLZ) design standards known in United States (or Europe) that incorporate the functional space a commercial vehicle would need to load and unload. Other studies have suggested that this lack of standards for CVLZs is an international concern. An Organisation for Economic Co-operation and Development (OECD) study on goods delivery challenges found that because of a lack of awareness and knowledge, many delivery facilities in many cities are ill-designed, including the issue of parking places being too small for freight delivery [7]. A study in Italy noted that a lack of functionality in the size of commercial vehicle parking zones limits the operation of truck parking and leads to the illegal occupation of road space outside the load zone [8].

The need for freight delivery loading space is exacerbated by increases in urban populations, e-commerce and home deliveries. Freight infrastructure faces increasing pressure as online shopping becomes more prevalent. In the United States, on average, e-commerce has grown by about $15 \%$ annually since 2010 , and in 2018 e-commerce accounted for more than $40 \%$ of total retail growth [3,9]. In Europe, the EU's clean and better transport program (CVITAS) predicts that by 2025 online retailing will be $20 \%$ of all retailing [10].

Current CVLZs are not well-designed to accommodate safe, efficient and reliable deliveries. This insufficiency affects all road users, and it is therefore important to understand current practices, standards, and gaps for designing a CVLZ.

The goals of this research were as follows:

1. through observed and simulated urban deliveries, understand the minimum operating space required during urban loading/unloading activities around a commercial vehicle and

2. develop measurements that can be used to support design guidelines for commercial vehicle operating envelopes on urban streets.

The term operating envelope is used in this study to describe the area required around a parked commercial vehicle to safely and comfortably load goods, unload goods and manoeuvre accessories such as hand trucks until the goods have reached the sidewalk. 


\section{LITERATURE REVIEW}

A literature review revealed that there is little oversight of or regulations for the design considerations for CVLZs. While this review focused on the United States, the review also explored international sources, but specific CVLZ design recommendations were not discovered.

In the United States, a CVLZ typically designates curb space for commercial vehicles to load/unload goods for a specified amount of maximum time, and this zone typically requires payment or a valid CVLZ permit. Cities across the United States have differing rules and regulations for these zones, but they can be generalized to include a paid permit and signage to indicate the constraints within the loading zone. Figure 1 shows a typical CVLZ sign as used in the city of Seattle [11].

There is minimal information about CVLZ design and envelope requirements in the major geometric, traffic control and street design guidebooks used by planners and engineers. The Manual on Uniform Traffic Control Devices, a commonly used resource with national standards for roadways in the United States, includes detailed information about appropriate signage and grades for commercial vehicles but does not include clear standards for the design and dimensions of a CVLZ [12].

In the American Association of State Highway and Transportation Officials 'A Policy on Geometric Design of Highways and Streets', guidelines are suggested for urban parking lanes. These include a width sufficient to accommodate delivery vehicles and serve as a bicycle route, allowing a bicyclist to manoeuvre around a vehicle's open door. The length of curb space allocated to each parking spot is not included [13].

The National Association of City Transportation Officials (NACTO) is a non-profit association of major North American cities that publishes design guidelines for various urban planning elements and modes such as bikes, transit and freight [14]. NACTO acknowledges that the operational envelope required for comfortable and safe movements is different for all modes, and that freight requires additional space for hand and cart movement. One of the freight delineations is for commercial vehicles and light trucks, which are defined as 'trucks generally used for carrying goods from ex-urbanized logistic centers to the city'. NACTO

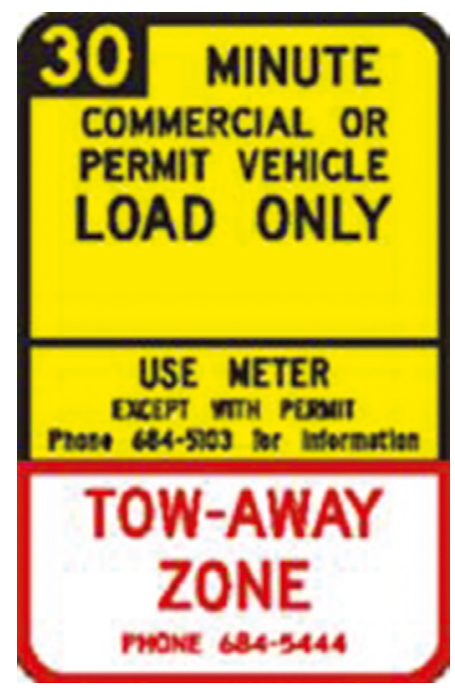

Figure 1: Typical commercial vehicle loading zone (CVLZ) signage [11]. 
identifies the general dimensions of commercial vehicles and light trucks as 7-10 m (23-33 $\mathrm{ft})$ long and $2 \mathrm{~m}(6.5 \mathrm{ft})$ wide. NACTO also recommends that box trucks with a width of 2.4 $\mathrm{m}(8 \mathrm{ft})$ have a parking spot $3.4 \mathrm{~m}(11 \mathrm{ft})$ wide to incorporate the buffer space required for the door zone. Although NACTO recognizes that additional space is required for freight parking to support freight loading/unloading activities, there is no additional information about the length of a commercial vehicle parking spot.

A study that used focus groups to learn from truck drivers about urban deliveries found that an impediment to urban freight activity was loading areas with insufficient space. The drivers recommended that curb space be at least $30 \mathrm{ft}(9 \mathrm{~m})$ long [15].

One of the few reports to explore truck access and parking, 'Truck Movement and Access in Urban Areas', noted that if traffic engineers considered the unique needs of urban freight in their practice, then the transportation ecosystem at large would improve [16]. A section on load zones addressed the problems of on-street load zones, which included being inconveniently located, not being sufficiently in number and poor design and layout (e.g. with the potential for collisions between vehicles and roadside objects such as poles, verandas and street lights). Although this article did not identify ideal on-street commercial vehicle parking dimensions, it included recommended minimum dimensions for a loading bay, which may be used as a proxy for on-street CVLZ dimensions:

- Light rigid two-axle truck: length $6.6 \mathrm{~m}$, width $2.1 \mathrm{~m}$ and wheelbase $3.7 \mathrm{~m}$.

- Heavy rigid three-axle truck: length $11.0 \mathrm{~m}$, width $2.5 \mathrm{~m}$, wheelbase (to midpoint of rear axles) $5.5 \mathrm{~m}$.

- Articulated truck with three-axle tractor: overall length $17.0 \mathrm{~m}$, width $2.5 \mathrm{~m}$, tractor wheelbase $3.7 \mathrm{~m}$, kingpin to midpoint of trailer axles $8.6 \mathrm{~m}$. [16].

The literature review did not find direct acknowledgment that urban freight activities require envelopes around trucks to support urban load and unload activities. The standard design sources and manuals to support planners and engineers responsible for installing transportation infrastructure did address the space required for parking trucks but did not account for the envelope needed around that parked truck that is necessary for the safe and effective loading and unloading goods.

\section{FIELD OBSERVATIONS}

The research team observed 25 urban delivery operations in the Seattle area to capture how they were affected by both delivery characteristics and the surrounding infrastructure. The research team designed a data collection form that captured 15 aspects of delivery characteristics.

Delivery location, date and time data served as an organizing tool. This variable tied the observation to a specific location and allowed the research team to collect information on the built environment around the truck after the delivery observations. If the delivery occurred at a CVLZ, details regarding the signage were recorded.

The observed truck categorized the delivery vehicle on the basis of the number of axles. The driver and passenger truck door type was also recorded because they affected how the courier exited the truck. The door types included swing-out doors, sliding doors or no door. The cargo compartment door location (back end, passenger side or driver side) and cargo vehicle door type (manual lift, roll up, one door opens out, two doors open out or other) were recorded because it affected how the courier interacted with the truck and moved goods in the space around the truck. 
Exiting/entering truck behaviour recorded the movements the courier initially made either outside or inside of the truck. The decision of which door to use in exiting may have been influenced by the built environment at the time of observed delivery. The courier may have used exit points from the truck on the driver side, passenger side or back end (by traveling within the truck and out through cargo compartment) and proceeded with delivery activities.

Accessories used and accessory path complemented the type of goods delivered and recognized that delivery accessories occupy space outside of the vehicle during the sorting, loading and unloading process. The type of accessories used in a delivery could include ramps, cones, hand trucks, dollies and pallet jacks, plus any other observed accessories. The location of the accessory before it is used noted whether it was stored on the outside or inside of the truck, and when it was disengaged from the truck for the delivery, as well as where it may have been temporarily placed outside of the truck.

Courier path to access cargo was an important category to capture because it described the courier's dynamic movements and activities around the delivery truck. The courier's choice to manoeuvre around the delivery truck was tracked in detail. Movements on either the outside of the driver side, back end, passenger side or front end of the truck were observed and described. This qualitative information was important to capture because it could be used to associate movement patterns with truck characteristics, the built environment and delivery characteristics.

Delivery characteristics and goods described served as a proxy for how movements around the vehicle occurred in response to the type of goods being delivered. The types of goods were noted because this influenced the accessories used in the delivery and directly affected the way the courier negotiated the delivery environment. Goods recorded included parcels, fresh produce, beverages and large bulky items such as furniture.

The number of couriers involved in the delivery was recorded because spatial needs and activity outside of the truck differed depending on the number of people actively involved in making the delivery.

Behaviour in response to the built environment captured any unique activity, behaviour or responses that occurred during the delivery. Often courier behaviour was directly affected by the built environment. For example, if the loading/unloading activity occurred adjacent to a transit lane, the courier may have chosen more inconvenient or inefficient behaviour to avoid conflict with that lane. Any outstanding or unusual courier behaviour was also recorded because this served as a proxy to the human aspect of decision-making and delivery operations at a curb space or on the road.

The built environment around the truck was described and included information about adjacent bike lanes, sidewalks, transit lanes, buffer lanes and curb use.

\subsection{Field observation results}

The deliveries observed occurred in a range of urban environments in the Seattle area and included CVLZs adjacent to sidewalks and bike and transit lanes. The majority of the 25 delivery vehicles observed (18 trucks) had only two axles and all were a single unit (no trailer). These vehicles, often called box trucks, are commonly used to make urban deliveries in the Seattle area. Twenty of the 25 deliveries were completed by a single person who was both the driver and moved the freight. These observations indicated that adequate space for opening doors should be provided on at least the driver's side of the vehicle for safe and comfortable ingress and egress. Eighteen of the observed vehicles had swing-out doors, which indicated that at a minimum, a commercial vehicle operating envelope should include space for the opening doors. 
Most of the 25 observed vehicles had cargo compartments access (17 trucks) located at the back end of the vehicle as opposed to the side of the vehicle. This may indicate that additional space required for the driver/courier to organize goods, load accessories and manoeuvre with accessories may be needed mostly at the back of a CVLZ.

Only three of the vehicles had a back-end powered lift gate, which is necessary for heavy loads, but those that did have a gate needed significantly more space to operate. Curbs or narrow parking lanes were observed as a hindrance for the convenient use of the lift gate. Narrow parking lanes meant that the lift gate was overhanging into the adjacent lanes or sidewalk. In some cases, Curbs obstructed lift gate operations and did not allow the lift gate to sit flush against the pavement.

Hand trucks were the most commonly used accessory (13 deliveries) and therefore the turning radius of a hand truck around the vehicle is important to consider. Other accessories observed were rolling bins and hampers ( 4 deliveries), ramps (1 delivery) and pallet jacks (3 deliveries). The freight was hand carried without accessories in four of the deliveries.

The envelope location where the couriers operated varied, but most were behind the vehicle (11 deliveries). This included walking past the back end or participating in loading/unloading activities at the back end of the vehicle. Seven of the 25 observed delivery activities were on the driver's side because some vehicles had cargo doors on the vehicle's side. Little to no activity was observed in front of the vehicles.

\section{SIMULATED DELIVERIES}

While the 25 observed deliveries provided information on how and where freight activities occurred in the freight envelope, the dimensions of the movements of those delivery activities could not be measured because of safety concerns and time constraints. The next step for the research team was to capture precise quantitative measurements of the movement location around the commercial vehicles during a delivery.

The research team collaborated with three delivery organizations: a university-based moving service (company A), a large, multinational package delivery company (company B) and a regional produce delivery company that supplied restaurants and grocery stores (company $\mathrm{C}$ ). The research team requested the participating organizations to volunteer 1 hour at their respective facilities and to make their typical urban delivery vehicles, accessories and goods available for the simulated delivery. This allowed the research team to observe and record courier and accessory movements around parked commercial vehicles. The goal of the data collection method was to measure and record movements around a vehicle to understand the minimum operating envelope needed around a commercial vehicle.

The three companies provided seven trucks of different sizes and types. The following aspects were recorded for each simulated delivery:

Closed vehicle footprint. The closed vehicle footprint was the commercial vehicle's measurements without any possible extensions engaged. The truck's overall dimensions, including its length, width and height, were recorded. The team measured the truck at its widest, including wheel nuts, protruding lights, mirrors and other details of the vehicle that extended the envelope.

Open vehicle footprint. The open vehicle footprint was the vehicle's measurements when all parts of the vehicle were extended for delivery operations. This included opening all doors and hatches and extending all accessories such as ramps and lift gates.

Active vehicle footprint. The active vehicle footprint was the area around the vehicle used by the courier plus the accessories used to complete the simulated delivery which included the space alongside and in the back of the vehicle used as part of the loading or unload of the truck. 
The researcher asked the courier to complete a typical delivery as in an urban area and to indicate the minimum amount of space they would need. As the courier responded by physically showing the space needed and, in some cases, the additional space they desired, the location of the courier and accessories' movements were marked with chalk. The chalk markings indicated the courier's movements, as well as the locations, dimensions and movements of the delivery equipment, including turning radii for equipment such as hand trucks and dwelling spots for the accessories while they were loaded. These chalk markings were then denoted with letters, measured and documented. For measurements located directly to the side or directly behind the vehicle, the measurements were documented as distance from the vehicle, and for measurements located at a diagonal, the corner of the truck was used as the nearest location to the measured point. Example results from the measurement process are shown for one vehicle in Figure 2 along with the simulation's measurement key in Figure 3.

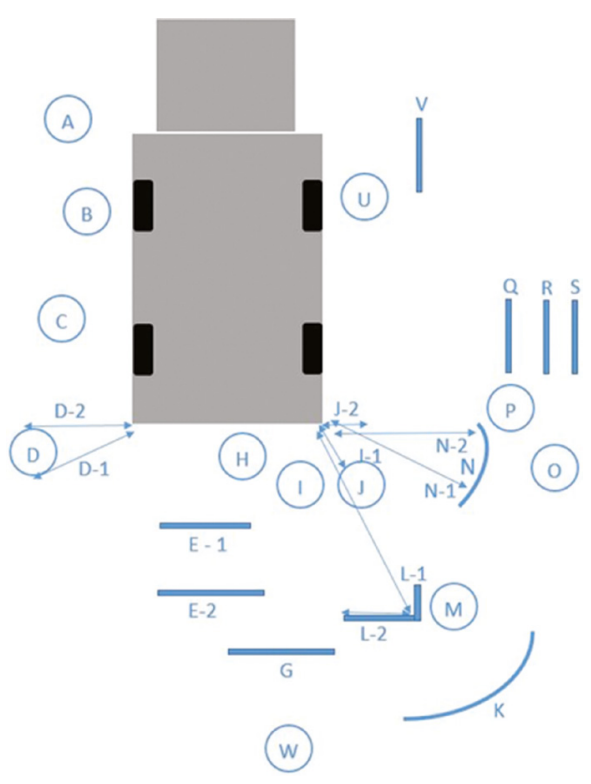

Figure 2: Example from the measurement of a simulated delivery.

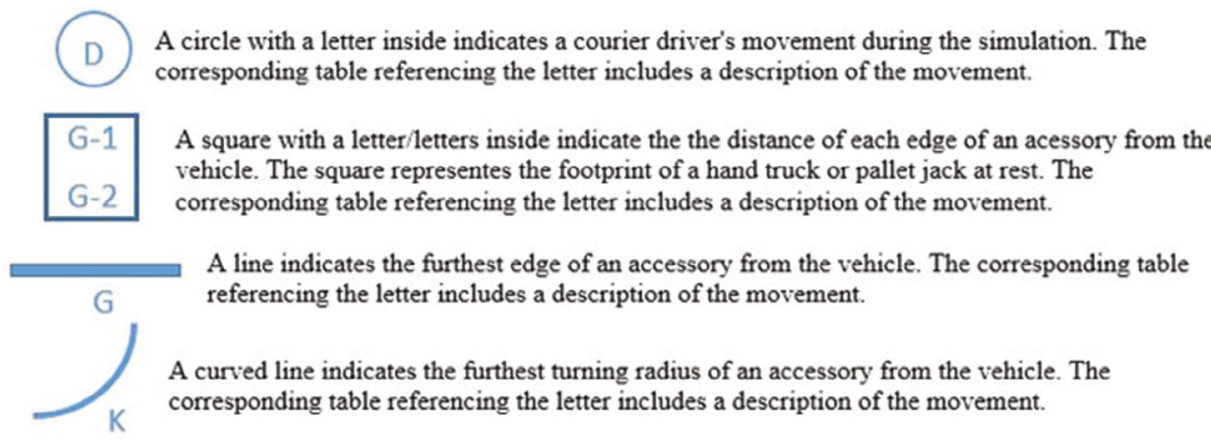

Figure 3: Measurement key. 
Interviews. The couriers participating in the simulation were also interviewed to better understand their decision-making and their experiences making urban deliveries. These interviews identified actions by couriers that might need to be considered in developing envelopes. Examples included requiring space to prop up a hand truck next to the commercial vehicle and the importance of room to deaccelerate at the bottom of a ramp when running a heavy load on a hand truck down the ramp.

\section{SUMMARY OF FINDINGS}

Through the 25 field observations and seven simulated deliveries, three major factors were found to significantly affect the safe and workable range of an operating envelope:

1. the driver and passenger door opening swing space,

2. the delivery type (unassisted or assisted with accessories),

3. the cargo door type at the back end of the vehicle.

Table 1 covers the length and widest point of each commercial vehicle in the simulation, which included the driver and passenger door opening swing space. The width measurement shown is either the swing span of the driver and passenger door fully extended, or if the vehicle did not have swing-out doors (a truck with sliding doors), then the widest portion of the vehicle itself. The width with door swing or widest dimension of vehicle covers the minimum space required for the vehicle width.

The dimensions in Table 1 provide a measure of the space required at a CVLZ on the basis of the type of truck and the doors on the truck. This space forms the interior edge of the truck envelope in which delivery activities occur.

Table 1: Truck footprint in centimetres (inches).

\begin{tabular}{lrlll}
\hline Commercial vehicle type & $\begin{array}{l}\text { Truck } \\
\text { length }\end{array}$ & $\begin{array}{l}\text { Truck } \\
\text { width with } \\
\text { mirrors }\end{array}$ & $\begin{array}{l}\text { Width with door } \\
\text { swing or widest } \\
\text { dimension of vehicle }\end{array}$ & $\begin{array}{l}\text { Width of one } \\
\text { door }\end{array}$ \\
\hline $\begin{array}{l}\text { Company A: box truck } \\
\text { with lift gate }\end{array}$ & $675(266)$ & $259(102)$ & $422(166)$ & $109(43)$ \\
$\begin{array}{l}\text { Company A: box truck } \\
\text { with lift gate }\end{array}$ & $1005(396)$ & $269(106)$ & $422(166)$ & $104(41)$ \\
$\begin{array}{l}\text { Company B: package car } \\
\text { with sliding doors }\end{array}$ & $2045(805)$ & $300(118)$ & $302(119)$ & $\begin{array}{l}\text { N/A (Sliding } \\
\text { door) }\end{array}$ \\
$\begin{array}{l}\text { Company B: box truck } \\
\text { with ramp and lift }\end{array}$ & $1023(403)$ & $269(106)$ & $378(149)$ & $64(25)$ \\
$\begin{array}{l}\text { Company C: delivery } \\
\text { van }\end{array}$ & $599(236)$ & $243(96)$ & $384(151)$ & $91(36)$ \\
$\begin{array}{l}\text { Company C: box truck } \\
\text { with ramp }\end{array}$ & $767(302)$ & $304(120)$ & $384(151)$ & $114(45)$ \\
$\begin{array}{l}\text { Company C: box truck } \\
\text { with lift }\end{array}$ & $980(386)$ & $320(126)$ & $406(160)$ & $106(42)$ \\
\begin{tabular}{l} 
Maximum dimension \\
\hline
\end{tabular} & $1,023(403)$ & $300(118)$ & $422(166)$ & $109(43)$ \\
\hline
\end{tabular}


Table 2: Envelope dimensions in centimetres (inches).

\begin{tabular}{|c|c|c|c|}
\hline Delivery type & $\begin{array}{l}\text { Delivery activity location and } \\
\text { accessories }\end{array}$ & $\begin{array}{l}\text { Workable } \\
\text { minimum cm } \\
\text { (inches) }\end{array}$ & $\begin{array}{l}\text { Workable maximum } \\
\mathrm{cm} \text { (inches) }\end{array}$ \\
\hline $\begin{array}{l}\text { Unassisted delivery } \\
\text { (no accessories) }\end{array}$ & $\begin{array}{l}\text { Side } \\
\text { Back end }\end{array}$ & $\begin{array}{l}64(25) \\
74(29)\end{array}$ & $\begin{array}{l}89(35) \\
\text { NA }\end{array}$ \\
\hline $\begin{array}{l}\text { Delivery with hand } \\
\text { truck }\end{array}$ & $\begin{array}{l}\text { Back end } \\
\text { Side }\end{array}$ & $\begin{array}{l}130(51) \\
272(107)\end{array}$ & $\begin{array}{l}168(66) \\
\text { NA }\end{array}$ \\
\hline $\begin{array}{l}\text { Pallet jack assisted } \\
\text { delivery }\end{array}$ & $\begin{array}{l}\text { Back end } \\
\text { Side }\end{array}$ & $\begin{array}{l}282(111) \\
191(75)\end{array}$ & $\begin{array}{l}454(179) \\
\text { NA }\end{array}$ \\
\hline $\begin{array}{l}\text { Lift gate-assisted } \\
\text { delivery }\end{array}$ & $\begin{array}{l}\text { Back end with lift gate only } \\
\text { Back end with lift gate and } \\
\text { pallet jack-assisted delivery }\end{array}$ & $\begin{array}{l}193(76) \\
475(187)\end{array}$ & $\begin{array}{l}256(101) \\
711(280)\end{array}$ \\
\hline $\begin{array}{l}\text { Ramp-assisted } \\
\text { delivery }\end{array}$ & $\begin{array}{l}\text { Back end: ramp only } \\
\text { Back end: ramp- and hand } \\
\text { truck-assisted delivery }\end{array}$ & $\begin{array}{l}401(158) \\
577(227)\end{array}$ & $\begin{array}{l}\text { N/A } \\
\text { N/A }\end{array}$ \\
\hline $\begin{array}{l}\text { Cargo door type } \\
\text { back end of vehicle }\end{array}$ & $\begin{array}{l}\text { Back end: roll up door } \\
\text { Back end: door open out }\end{array}$ & $\begin{array}{c}0(0) \\
79(31)\end{array}$ & $\begin{array}{l}\text { N/A } \\
\text { N/A }\end{array}$ \\
\hline
\end{tabular}

Table 2 covers the delivery types (assisted or unassisted with accessories) and the cargo door types at the back end of the vehicles. These envelope dimensions are added to the footprints of the trucks seen in Table 1. The delivery envelope is this widest portion of the vehicle, plus the minimum space required along the sides of the vehicle for the courier/driver. The workable envelope minimum is an average of measurements that were noted to be needed for the courier. The workable maximum is the additional space which, in some cases, the couriers indicated would be desirable and more comfortable but not necessary.

The envelope's dimensions increase if accessories are used. For a hand truck, the workable minimum includes room to rest a hand truck at an angle on the vehicle. These measurements were calculated by assuming that a lift gate is not used. On the side, the workable minimum includes the measurements of a hand truck tilted on the passenger side (which is safer than using the street side) of a vehicle and the extra space needed to accommodate the turning radius of the hand truck.

A pallet jack or pallet truck is a basic, often hand powered, form of a fork lift. For this accessory, the workable minimum is the smallest space needed to operate behind a commercial vehicle. These measurements exclude the additional space required for a lift gate behind the vehicle. The side measurement is the space the courier needs or wants to operate a pallet jack along a commercial vehicle. This measurement captures manoeuvring space, pallet jack dimensions and possible parcel overhang off the pallet jack. 
If a commercial vehicle is equipped with a lift gate, this accessory is located on the back end of the vehicle. The minimum distance in Table 2 is the smallest width measurement of the lift gates in the simulation, and the maximum is the largest width of a lift gate in the simulation. Because utilizing a pallet jack is dependent on having a vehicle with a lift gate, the second set of measurements, back end with lift gate and pallet jack-assisted delivery, adds the workable minimum and maximum of pallet jack-assisted delivery to the lift gate measurement.

In Table 2, the measurement associated with a delivery using a ramp, back end - ramp only, is the additional space required behind a vehicle for just a ramp to extend. Because ramps are often associated with using a hand truck, back end - ramp- and hand truck-assisted delivery includes the measurements of a ramp and the extra space needed to use a hand truck (deceleration on the ramp and turning radius) as well.

Commercial vehicles have different designs that affect the amount of space required to operate around the vehicle. One factor that affects the operating envelope is the cargo door type at the back end of the vehicle, which can include a manual lift, roll up or open one extended, or if the vehicle does not have swing-out doors and has sliding doors, then the widest portion of the vehicle itself.

The workable range of dimensions in Table 2 ultimately provides a recommendation for the optimal envelope dimensions of a CVLZ. The envelope dimensions are added to the footprint of the truck. This footprint is the widest point of a commercial vehicle when the vehicle's cargo doors are closed, but the CVLZ should account for door swing space. The delivery envelope is this widest portion of the vehicle, plus the minimum space required along the sides and back of the vehicle for the courier. The workable envelope minimum in Table 2 is an average of measurements that were noted to be needed for the courier. The workable maximum is an average of the measurements that were noted to be desired by couriers based on observations of and interviews with the couriers.

As an example of using these measurements, if our project partner the City of Seattle wanted to install a CVLZ in an area with a number of small restaurants, the following calculations would result in safe and workable CVLZs. The typical truck serving this area is a mid-size box truck like the company $\mathrm{C}$ box truck in Table 1 . This truck requires a length of $7.7 \mathrm{~m}(25 \mathrm{ft})$ and width of $3.1 \mathrm{~m} \mathrm{(10} \mathrm{ft).} \mathrm{This} \mathrm{is} \mathrm{the} \mathrm{truck} \mathrm{footprint.} \mathrm{The} \mathrm{driver's} \mathrm{doors} \mathrm{swing}$ out and increase the width required to $3.8 \mathrm{~m}$ (12 ft $7 \mathrm{in}$ ), so the CVLZ should account for the doors. Table 2 can be used to add to the truck footprint to develop the truck delivery envelope. This area of Seattle has many small deliveries, so hand trucks are commonly used in conjunction with a ramp, as opposed to pallet jacks and lift gates. The use of a ramp adds $5.7 \mathrm{~m}$ (227 inches) to the back of the truck (for the ramp and hand truck manoeuvring and turning room). As seen in Table 1, in addition, $0.6 \mathrm{~m}$ (24 in) will be required for the driver to walk alongside the truck to the back. This results in a CVLZ with a width of $3.7 \mathrm{~m} \mathrm{(12} \mathrm{ft)}$ and length of $13.4 \mathrm{~m}(44 \mathrm{ft})$.

\section{CONCLUSIONS}

This research determined that there are no standard measures of the space (an envelope or buffer) required around commercial vehicles for safe and effective unloading and loading of goods between the delivery vehicle and the sidewalk. The research team observed a number of deliveries to determine how couriers exit their vehicles, where they loaded and unloaded the freight, and what accessories they commonly used. This guided the next step, which was to measure the minimum required space and ideal space used by couriers to unload or load their cargo with and without accessories. 
The resulting envelope measurements are specific measurements that can be used to set design standards for safer and more effective CVLZs. A city concerned about a right-size CVLZ for an effective delivery envelope can use these measurements as a guide. The city can determine the typical size of commercial vehicles that serve its city and add the envelope measurements to the dimensions of the trucks. For many American urban areas, for example, according to standardized classification guides [17] this is a class 5, two-axle, six-tire, single-unit "box" truck. The envelope can be further adjusted on the basis of commonly used accessories.

Ultimately, this information can be added to design guides to support planners and engineers as they install CVLZs to support effective urban deliveries.

\section{ACKNOWLEDGMENTS}

This work has been funded by the US Department of Transportation's University Transportation Center Program grant through the Pacific Northwest Regional University Transportation Center (PacTrans).

\section{REFERENCES}

[1] National Complete Street Coalition, available at https://smartgrowthamerica.org/program/national-complete-streets-coalition/, (accessed 12, March 2019).

[2] Smart Growth America, available at https://smartgrowthamerica.org/, (accessed 12 March 2019).

[3] The Final 50 Feet, Urban Goods Delivery System, Final Report, Supply Chain and Logistics Center, University of Washington, available at https://depts.washington.edu/ sctlctr/sites/default/files/SCTL_Final_50_full_report.pdf, 2019.

[4] Goodchild, A., Ivanov, B., McCormack, E., Moudon, A., Scully, J., Leon, J.M. \& Giron Valderrama, G., Are Cities' Delivery Spaces in the Right Places? Mapping Truck Load/ Unload Locations. City Logistics 2: Modeling and Planning Initiatives, pp.351-368, 2018.

[5] Wygonik, E., Bassok, A., Goodchild, A., McCormack, E. \& Carlson, D., Smart growth and goods movement: emerging research agendas. Journal of Urbanism: International Research on Placemaking and Urban Sustainability, 8(2), pp.115-132, 2015.

[6] Health and Safety Executive, Delivering Safely, available at http://www.hse.gov.uk/ workplacetransport/information/cooperation.htm, (accessed 12 March 2019).

[7] Delivering the Goods, 21st Century Challenges to Urban Good Transport, Organization for Economic Co-Operation and Development, E118628, available at https://www.itfoecd.org/sites/default/files/docs/03deliveringgoods.pdf, (accessed 19 March 2019).

[8] Dezi, G., Dondi, G. \& Sangiorgi, C., Urban freight transport in Bologna: Planning commercial vehicle loading/unloading zones. Procedia-Social and Behavioral Sciences, 2(3), pp.5990-6001, 2010.

[9] US Census Bureau News, March 13 2019, Quarterly Retail E-Commerce Sales 4th quarter 2018, available at https://www.census.gov/retail/mrts/www/data/pdf/ec_current.pdf (accessed 19 March 2019).

[10] CIVITAS Policy Note, Smart Choices for Cities, Making Urban Freight Logistics More Sustainable, available at https://civitas.eu/sites/default/files/civ_pol-an5_urban_web.pdf, (access 12 March 2019).

[11] Seattle Department of Transportation, Can I Park Here, available at https://www.seattle.gov/Documents/Departments/SDOT/ParkingProgram/CanIParkHereBrochure.pdf, 2015 (accessed 19 March 2019). 
[12] Federal Highway Administration, Manual on Uniform Traffic Control Devices for Streets and Highways, 2009 ed.

[13] American Association of State Highway and Transportation Officials, The Green Book, A Policy on Geometric Design of Highways and Streets, 6th ed., 2011.

[14] The National Association of City Transportation Officials (NACTO), Urban Street Design Guide. Island Press, 2013.

[15] Pivo, G., D. Carlson, M. Kitchen, \& D. Billen. "Learning from Truckers: Truck Drivers' View on the planning and Design of Urban and Suburban Centers. Journal of Architectural and Planning Research 19(1), pp. 12-29, 2002.

[16] Ogden, K.W., Truck movement and access in urban areas. Journal of Transportation Engineering, 117(1), pp.71-90, 1991.

[17] U.S. Department of Transportation, Truck Monitoring Guide, Vehicle Types, available at https://www.fhwa.dot.gov/policyinformation/tmguide/tmg_2013/vehicle-types.cfm (accessed 21 March 2019) 